\title{
SENS, Alex. Corações ruidosos em queda livre. Guaratinguetá: Penalux, 2018.
}

\section{Robson Batista dos Santos Hasmann}

Instituto Federal de Educação, Ciência e Tecnologia de São Paulo (IFSP), São Paulo, São Paulo / Brasil

robson.hasmann@ifsp.edu.br

http://orcid.org/0000-0002-4003-6142

Janela ou corredor? Qualquer que seja sua escolha quando o funcionário da empresa fizer essa pergunta no guichê, a resposta será sempre a opção de assumir um ponto de vista, que, de certa forma, determinará seu olhar sobre a viagem. Se janela, a paisagem, passando em quadros ou estancada pelo engarrafamento, será mais chamativa do que a poltrona, caso a escolha seja o corredor. Será? Não seria, talvez, cada um dos passageiros uma boa história em si?

Foi nessa problemática que Alex Sens apostou para abrir Corações ruidosos em queda livre, conjunto de três narrativas que têm a morte como eixo temático. O título impressiona, assim como seu romance $O$ toque frágil dos mutilados (2016), texto com o qual tornou-se reconhecido, pois com ele foi indicado para a final do Prêmio São Paulo de Literatura e a semifinal do Oceanos daquele ano. Pelas indicações, vê-se que o autor já circula forte nos meios literários atuais. O escritor, que em 2012 vencera o Prêmio Governo de Minas Gerais, se insere entre as promessas da literatura brasileira, juntamente com diversos autores nascidos no final dos anos 80: os já famosos Julián Fuks, Carol Bensimon e Ana Paula Maia, bem como os estreantes Aline Bei, Tiago Feijó e Tiago Ferro ${ }^{1}$ - só para citar alguns.

O livro de Sens representa a aposta de uma pequena casa editorial que há cerca de dez anos tem trabalhado tanto com "publicações independentes" quanto com obras de difícil acolhimento em editoras grandes. Trata-se de

\footnotetext{
${ }^{1} \mathrm{O}$ critério adotado para compor a galeria a que nos referimos considerou as premiações e indicações recebidas nos últimos cinco anos.
} 
três novelas, gênero que tem sido desidratado no mercado, visto ora como romance ora como conto - forma, aliás, usada pela editora para catalogação. Talvez por ser uma vertente meio adormecida da literatura brasileira, merece algumas considerações antes de, efetivamente, adentrarmos nas narrativas de Alex Sens. Refletir sobre esse gênero auxiliará a observar o livro com relação à arquitetura minuciosa e instigante das três tramas.

A princípio, pode soar anacrônico trazer à baila a problemática dos gêneros. Na pós-modernidade, época de frágeis fronteiras, ao propor algumas discussões acerca desse tópico da crítica literária, um simples argumento seria suficiente: há muito passamos da etapa em que se acreditava na pureza dos gêneros. Acontece, porém, que mesmo a crítica pós-estruturalista tendo se debruçado sobre questões temáticas densas dentro dos textos literários, a preocupação, do escritor e da crítica, com o gênero é necessária, também, por outro argumento igualmente simples: literatura é forma. Nesse sentido, vale a pena nos lembrarmos, por exemplo, das palavras de Georg Lukács em A teoria do romance, cujas reflexões ensinaram que "toda a forma [literária] é a resolução de uma dissonância fundamental da existência, um mundo onde o contra-senso parece reduzido a seu lugar correto, como portador, como condição necessária do sentido" (LUKÁCS, 2000, p. 61). Por essa citação, que traz muito mais do que sociologismo, evidencia-se a imbricada relação entre a forma literária e a vida.

Trazendo a discussão para os tempos atuais, um renomado crítico e escritor consagrado assinalou a dificuldade - e a importância - de haver conhecimento do gênero com o qual se trabalha. Luiz Antonio de Assis Brasil, em Escrever ficção: um manual de criação literária (2019), explana sobre a novela nos seguintes termos:

Nossa língua ainda preserva as duas denominações, romance e novela, designando gêneros diferentes, mas isso está caindo em desuso. Entendo, todavia, que o ficcionista deve saber qual o gênero de sua proposta literária, pois isso evitará desvios de rota que poderão comprometer o resultado final do texto [...]. (BRASIL, 2019, p. 27).

Se a necessidade de apreender o gênero serve de conselho prático para a escrita, a compreensão do que venha a ser, em língua portuguesa, uma novela pode ser paralisante se o ato criativo quiser moldar-se a ela. A dificuldade aparece, inicialmente, na metodologia de alguns críticos. Os gêneros literários e suas transformações ao longo do tempo são 
frequentemente apresentados em confronto, isto é, a definição do conto, por exemplo, é feita a partir daquilo que não é conto, mas sim romance, e vice-versa. Com a novela ocorre o mesmo.

Para se ter dimensão da complexidade desse gênero, colocamos duas "definições". A primeira é do próprio Luiz Antonio de Assis Brasil, para quem a distinção entre romance e novela está no "núcleo de conflito", nomenclatura que ele prefere a enredo. Segundo sua expectativa, a novela possuiria "um núcleo de conflito e poucos personagens [...]; o romance, em vez de trabalhar com um núcleo de conflito, trabalha com um tema, em torno do qual giram vários conflitos, cada um com seus personagens" (BRASIL, 2019, p. 341-342, grifo do original).

Já para um crítico mais tradicional como Massaud Moisés, a novela possuiria sucessividade de "células dramáticas" (termo com ele designa o conflito ou a ação da narrativa). Para ele, a "agregação [das] unidades narrativas, seguindo uma ordenação cronológica, que sugere a perspectiva do mundo fornecida pelo calendário" (MOISÉS, 2006, p. 114) seria a forma da novela.

Como se vê, o critério do "núcleo", de conflito ou dramático, se opõe nas duas concepções. Enquanto para Brasil (2019) o núcleo é único, para Moisés (2006) existem vários pequenos conflitos em sucessão cronológica.

Essa discussão teórica parece sobrar em uma resenha; todavia, ela se faz necessária, mesmo que superficialmente, a partir de uma observação do mesmo Luiz Antonio de Assis Brasil: a de que, na literatura brasileira contemporânea, os livros denominados "romances" são, na verdade, novelas, gênero "de toda a literatura de jovens ficcionistas, tanto do Brasil como do exterior” (BRASIL, 2019, p. 342). A constatação amplia sua relevância quando recordamos que se trata da opinião de alguém que é responsável pela formação e profissionalização de dezenas de escritores nas últimas três décadas. ${ }^{2}$

Com efeito, a novela, enquanto forma literária e produto de mercado, não frutificou abundantemente no Brasil. Na origem moderna de nossa literatura, o texto de que mais se lembra é O alienista, de Machado de Assis. Ora conto ora novela, a narrativa, ainda que uma das mais relevantes de sua obra, tem uma forma pouco frequente (talvez seja caso único) no conjunto da produção do escritor carioca.

\footnotetext{
${ }^{2}$ O crítico coordena desde os anos 1980 oficinas de criação literária, inclusive sendo responsável pelo mestrado em escrita literária da PUC-RS, em Porto Alegre.
} 
Ainda sobre a ausência/presença do gênero na literatura nacional, é pertinente trazer à baila as reflexões de Ivan Teixeira (2010) em artigo que compara a prática editoral de Machado de Assis à de Edgar Allan Poe, também autor de narrativas curtas e pedra angular das teorias sobre o conto. $\mathrm{O}$ crítico tece algumas considerações sobre a forma novela a partir da publicação de $O$ alienista no jornal $A$ estação. Suas observações partem da questão da extensão do texto. Segundo o ex-professor da Escola de Comunicação e Artes da USP, esse aspecto é provocado pela organização das ações e pelo número de personagens.

Apoiados nessas reflexões sobre a novela, podemos voltar com mais clareza ao livro de Alex Sens. Como dissemos, compreendemos que trata-se de três novelas. A reflexão justifica-se porque permite analisar com mais cuidado o modo de organização das ações nas três narrativas e as implicações teóricas que elas provocam para se pensar a literatura nacional em nossos dias. Sob essa perspectiva, veremos que a primeira e a terceira se diferenciam pela unidade do ponto de vista.

Em "Corações ruidosos", a primeira novela, está ausente o núcleo conflituoso. Nesse texto, sobressai a revelação da vida íntima de inúmeras personagens que compartilham uma viagem rodoviária. Não interagem; mas, ao terem seus pensamentos revelados pelo narrador onisciente, é possível traçar alguns paralelos. O leitor, inserido no ônibus já em movimento aparentemente em uma tortuosa estrada, acompanha os pensamentos, as reflexões, os desejos e os medos de várias personagens. É, portanto, uma narrativa em que predomina a exploração da interioridade de anônimos. Esse recurso provoca a sensação de dispersão na leitura, mas contribui para a percepção de que os anônimos merecem também atenção. Aos poucos, se revelam os conflitos individuais, sempre interiores, sem causalidade evidente, por meio dos quais identificamos muitos núcleos, isto é, as amarguras e angústias dos passageiros. O que eles têm em comum é apenas o fato de estarem, casualmente, no mesmo espaço e compartilharem a mesma tragédia. Junto com os passageiros, somos devorados, ao fim da narrativa, pelo desfecho brusco - ainda que levemente previsível por causa da ausência de ação e interação entre as personagens. No ônibus, vale a pena seguir a forma cuidadosa e elegante com que as vozes silenciosas são construídas. $\mathrm{O}$ narrador tece, em diversos momentos, o fluxo das consciências com metáforas. Em certo ponto da viagem, uma das personagens especula: 
Sentiu saudade das coníferas no quintal, dos cachorros, da negra chuva de pássaros que perfurava o ar com seu canto azulado. Menos das cigarras. As cigarras que entravam em seus ouvidos e nele batiam suas asas de vidro, grelhando o silêncio com seus cantos de brasa. A viagem nunca acaba. Nunca nunca nunca. (SENS, 2018, p. 37).

Essa estratégia da linguagem vitaliza o texto, pois, dentre alguns dos desconhecidos passageiros, estão conflitos interiores que, enquanto tema literário, facilmente fariam bocejar. Seria o caso, por exemplo, do padre angustiado porque está entre a obediência aos dogmas e aos preceitos religiosos e o desejo sexual; ou da mulher que sofre violência doméstica.

A terceira novela, "Livre", tem formato epistolar. A imersão no universo íntimo das personagens se intensifica, pois a personagem Leonor, escritora de meia idade, escreve cartas ácidas a pessoas do estreito círculo de amizades: oito pessoas, cada uma destinatária das epístolas, com as quais ela parece estar fazendo um acerto de contas. Vemos que a morbidade dos escritos talvez seja consequência de dois eventos agudos: no intervalo de cinco dias, morre Heitor, o marido, e descobre um câncer no pulmão. Esses acontecimentos, que poderiam a priori sensibilizar o leitor, liberam a protagonista para expressar as palavras e desejos que o dia a dia reprimira por anos. A liberdade e o rancor ficam claros na carta destinada a Flora, a médica que lhe detectou a enfermidade: "[o câncer] rasgou todos os contratos que eu tinha feito comigo mesma e com a vida. Eu fiquei livre" (SENS, 2018, 118). Essa sentença, aparentemente marcada pela positividade, é complementada pelo desejo amargo: "Ah, Flora, como eu gostaria que você passassse para seus pacientes todo o câncer que eles pudessem ter" (SENS, 2018, p. 121).

$\mathrm{O}$ formato epistolar e a retomada das personagens, principalmente de Heitor, na maioria das cartas, dá unidade à narrativa. Chama atenção a escolha da última destinatária, Verônica, a terapeuta da narradora. Somente nessa oitava carta o leitor tem a revelação do núcleo dramático da trama.

Acerca da possibilidade de se ler esse texto como uma novela, é necessário registrar que, devido à extensão, dissipam-se duas características dos contos. A primeira é o "efeito de sentido único", trabalhada por Allan Poe, e a segunda a do knock-out, de Julio Cortázar. Nesse sentido, essas duas novelas ganham em qualidade, enquanto novelas, porque os acontecimentos conduzem, paulatinamente, sem pressa, ao desfecho. 
Saltamos propositalmente a segunda novela para abordá-la nos encaminhamentos finais desta resenha. Não por acaso, porque sem dúvida é a narrativa mais bem acabada do conjunto. Aqui, ganha relevância Lucas, um jovem que acompanha com afinco as performances artísticas e exposições de arte em uma galeria: todas voltadas à tematização e concretização da morte. O interesse em saber por que Lucas ama tanto a galeria - inicialmente parece que ele é um funcionário - ou a vontade de descobrir qual será a próxima performance se imbricam e conferem unidade ao enredo. A curiosidade do protagonista anda de par em par com a crítica à "indústria cultural". Cria-se, assim, na narrativa, uma atmosfera nonsense, que, afinal, é a melhor expressão para problematizar as performances bizarras típicas de programas televisivos sensacionalistas e que vez por outra invadem as bienais e exposições de arte.

A curiosidade de um jovem solitário pela morte artística provoca angústia. No entanto, assim como na primeira narrativa, a construção de um desfecho inusitado acaricia os sentimentos de medo e repugnância que as performances provocam. No fim, Lucas se mostra um sopro de humanidade em meio à banalização e mercantilização da morte, e da arte, porquanto, "a morte tem para ele o fascínio de todos os grandes mistérios da natureza humana reunidos" (SENS, 2018, p. 90).

Conto, novela ou romance? A forma épica sofre transformações ora mais brutais ora menos observáveis a olho nu. Obviamente, pensar a respeito das formações literárias não implica (não deve implicar) estabelecer critérios de hierarquia. Por outro lado, a observância do quanto se publica merece atenção tanto do historiador quanto do crítico literários, uma vez que as edições sinalizam inúmeras transformações sociais: o gosto do público, as formas de leitura, bem como as experiências e os experimentos individuais dos escritores. Entre o fim dos anos 1990 e início dos 2000 diziase que o conto era o gênero daquela época: a condensação das unidades e a breve extensão dos textos seriam traços marcantes de uma estrutura social cuja experiência de vida estava justamente rasgada pela velocidade, pela síntese, pela imagem. Passadas algumas décadas, em um período em que a palavra perde sentido assim que lida nas mídias sociais, não teria a novela a potência de estabelecer uma "justa medida" entre a emergência de mais histórias profundas juntamente com a necessidade da condensação e rapidez dos tempos? 


\section{Referências}

BRASIL, Luiz Antonio de Assis. Escrever ficção: um manual de criação literária. São Paulo: Companhia das Letras, 2019.

LUKÁCS, Georg. A teoria do romance: um ensaio histórico-filosófico sobre as formas da grande épica. Tradução, posfácio e notas José Marcos Mariani de Macedo. São Paulo: Duas Cidades: Editora 34, 2000.

MOISÉS, Massaud. A criação literária: Prosa I. 21. ed. São Paulo: Cultrix, 2006.

TEIXEIRA, Ivan. Conceito de conto em Poe \& Machado de Assis: $O$ Alienista como novela. Revista da Academia Brasileira de Letras, Rio de Janeiro, v. 63, p. 247-268, 2010. Disponível em: http://www3.eca.usp.br/ sites/default/files/form/biblioteca/acervo/producao-academica/002183655. pdf. Acesso em: 15 jan. 2019.

Recebido em: 24 de janeiro de 2020.

Aprovado em: 29 de maio de 2020. 